\title{
WICKING BEHAVIORS OF RING AND COMPACT-SIRO RING SPUN YARNS WITH DIFFERENT TWISTS
}

\author{
Yuzheng $\mathrm{Lu}^{1, *}$, Yang Wang ${ }^{1,2}$ and Weidong Gao ${ }^{1}$ \\ ${ }^{1}$ Key Laboratory of Science \& Technology of Eco-Textile, Jiangnan University, Ministry of Education, China, 214122 \\ 2 Jiangsai Textile Science \& Technology Co. Ltd., Suzhou, Jiangsu, China, 215000 \\ ${ }^{*}$ Corresponding author: Luyz@jiangnan.edu.cn
}

\begin{abstract}
:
In this study, the wicking properties of ring and compact-siro ring spun staple yarns were compared. The twist level, which is related to the structure of the staple yarns, was found to significantly influence the wicking property of the two kinds of yarn. Polyester staple fibers with $1.33 \mathrm{dtex} \times 38 \mathrm{~mm}$ were selected as the staple fiber material, and the effect of the twist level on the wicking property was investigated using the capillary rise method. The results show that with a decreasing twist coefficient, the wicking height increases with a decrease in yarn compactness. The compact-siro spun yarn showed better wicking properties owing to it special ply yarn structure. Furthermore, the tension property of the yarns decreased significantly with a decrease in the twist coefficient. Compact-siro spinning was carried out to obtain staple yarns with lower twist coefficients, and the yarns showed great improvement in terms of yarn strength, fiber straightness, and wicking properties. Thus, compact-siro spinning is an efficient method to improve the wicking properties of staple yarns.
\end{abstract}

\section{Keywords:}

Wicking property; capillary rise method; twist; staple yarns; compact-siro spinning

\section{Introduction}

The thermal and moisture comforts of fabrics are mainly dependent on the heat and moisture transport properties of clothing and the manner in which clothing helps to dissipate body heat during various types of physical activity [12]. The transmission of air, heat, and water vapor through a garment is the most important factor affecting comfort related to clothing, and the ability to transport vapor significantly influences the thermal and moisture comfort [13]. It has long been assumed that fabrics that absorb moisture tend to be more comfortable than those that do not. However, the relationship between comfort and moisture is complex; moisture transport is as important as absorption, especially for underwear and sportswear. This is perhaps why fibers such as Coolmax ${ }^{\mathrm{TM}}$, which have wicking properties, despite their very low moisture regains, are perceived as being comfortable to wear [5]. Therefore, the development of methods to improve fabric wicking is important for improved comfort.

The moisture transport property of the yarn significantly impacts on that of the fabric. Yarn can be divided into two categories: staple yarns and long filament yarns. Previous work on the wicking properties of staple yarns has produced a mathematical model for yarn wicking $[2,6]$. With increasing twist factor and packing density, the wicking height of lyocell and viscose ring-spun yarns decreases [1, 11]. Knitted fabrics made from polypropylene show better moisture transport properties than PET [7]. Furthermore, ring-spun yarns show better wicking properties than vortex-spun yarns [3].

Some studies have focused on the filament wicking property. Fabrics with $3 \mathrm{D}$ hierarchical $\mathrm{ZnO}$ nanowires fabricated on the filaments can potentially be used in water-harvest surfaces [15]. The wicking properties of polyamide 66 filaments were tested under different parameters, and the result shows that capillary rise heights tend to decrease with an increase in the filament twist coefficient [4]. Nanofibrous structures on polyamide filaments were found to impart better wicking properties [9]; such modified cross-sectional filaments exhibit a larger wicking height than that of the common ones, and with the increase in the twist level of the filament, the wicking height increases until reaching a maximum value, after which it decreases [14]. The moisture transfer properties of dyeable-PP, PET, PP, and Coolmax ${ }^{\mathrm{TM}}$ fibers were compared using samples with the same knitted structure, and the Coolmax ${ }^{\mathrm{TM}}$ fibers exhibited the best wicking properties [7].

In chemical fiber production, long filaments are often cut into staple fibers to simulate natural fibers, such as cotton, flex, and wool; the staple yarn structure can also simultaneously improve moisture transportation properties. Compared with long filaments, staple yarns' wicking properties are more significantly influenced by the twist coefficient and yarn structure. In this study, the twist effects on the wicking properties of ringspun and compact-siro spun staple yarns were compared; the improvement in the compact-siro spun staple yarns was analyzed based on the results of the experiment.

\section{Theory}

Wicking is the property of maintaining liquid transport within capillary pores formed between the surfaces of fibers and releasing water drops at the other end of the fibers. For both staple yarns and filament yarns, the wicking property is 
very complex and is determined by fiber parameters, liquid characteristics, and yarn structure [8].

First, the wicking height is related to the pore size. Theoretically, the maximum wicking height can be expressed as follows [14]:

$$
\mathrm{h}_{e q}=\frac{2 \gamma \cos \theta}{\rho g R_{s}},
$$

where $h_{\text {eq }}$ is the maximum wicking height; $\gamma$ and $\rho$ are the surface tension and density of the liquid, respectively; $\theta$ is the advancing contact angle of the liquid to the solid; $g$ is the acceleration due to gravity; and Rs is the mean static radius of the pores.

From Eq. (1), it is clear that the wicking height of yarns in a certain period is related to the size of the capillaries and the physicochemical characteristics of the liquid. The increase in the yarn twist level will lead to a decrease in Rs, and the wicking height $h_{\text {eq }}$ should increase proportionately.

Previous research has shown different trends when Eq. (1) was used. In the case of filament yarns, the wicking height first increases and then decreases with increasing twist level [14]. In contrast, for staple yarns, an increase in the twist level (from 325 to 400 twist coefficient) decreases the wicking heights of the viscose ring-spun yarns [11].

The trend of the filament wicking property to the twist level can be explained with Eq. (1) when the twist level is relatively low. An increase in twist level decreases the diameter of the pores in the filaments and simultaneously improves the wicking property. With a continuous increase in the twist level, some capillary channels will be blocked, leading to a decrease in the filament wicking property. The wicking property of the filament yarn can be influenced by the capillary size and the capillary channel amount. The initial twist is useful for the formation of capillaries, and too much twist may block capillary channels. That is why the wicking height first increases and then decreases with an increasing twist level.

On the basis of the above analysis, staple yarns should follow the same trend as filament yarns; however, previous research has not tested this systematically. The twist levels selected have been limited to short sections [1,11], and the integral influence of the twist effects on the wicking property of the staple yarns has not been expressed accurately. In this study, the twist effects on the wicking property of staple yarns were investigated experimentally.

\section{Experimental}

\subsection{Sample Preparation}

The yarn samples used were polyester staple yarns. As the moisture regain of polyester fibers is only $0.4 \%$, the wicking property of these staple yarns is only related to the structure of the yarns. The fibers were $1.33 \mathrm{dtex} \times 38 \mathrm{~mm}$, and the yarn count was 9.7 tex. Yarns were all spun on a Toyota RX300 ringing spun machine using ring spinning and compact-siro spinning processes, and the twist of the yarns ranged from 545 to $1260 \mathrm{t} / \mathrm{m}$ with a step of $65 \mathrm{t} / \mathrm{m}$ (correspondingly, the twist coefficient ranged from 170 to 390 with a step of 20). Ring-spun yarns cannot be produced with a twist under $545 \mathrm{t} / \mathrm{m}$.

\subsection{Capillary Rise Measurements}

The capillary rise method can be used to test the wicking property of yarns. The yarn should be kept vertically with the lower end immersed in liquid; spontaneous wicking occurs owing to capillary penetration and the absorption height is recorded as a function of time. From this, the absorption rate can be calculated.

A YG (B) 871 capillometer was used for the capillary rise measurement. The samples were placed vertically with the lower end dipped in a thin layer of a diluted potassium permanganate aqueous solution $(0.5 \%$, with a solution depth of $>0.01 \mathrm{~m}$ ). The absorption heights were measured after the yarn was dipped in the liquid. Each measurement was carried out 10 times with a 30-min wicking time. The mean wicking height values were regarded as the final result.

\subsection{Strength Measurements}

Yarn strength is a very important property in fabric production; it is significantly impacted by changes in the twist level. A YG063T was used to test the strength of the yarns. All samples were conditioned at $20 \square$ and $60 \%$ relative humidity for at least $24 \mathrm{~h}$. Each measurement was carried out 30 times, and the mean strengths were regarded as the final result.

\subsection{Yarn Structure Characterization}

The capillary channel size and amount are related to the structure of staple yarns. In order to express yarns structure in detail, a scanning electron microscope (SEM, Hitachi SU1510) was used. The most suitable magnification for longitudinal yarn structure characterization was approximately $100 \times$.

The cross-sectional structure of the yarn was observed using a YG002C fiber detection system. First, red wool fibers were circled from the pure polyester yarn, which had the same line density, and then a slice is made with the Y172 hashsler slicer. The fiber was photographed with a microscope at a magnification of $500 \times$. In order to prevent the deformation of yarn during the extrusion process of wool fiber, the staple yarn was pretreated with collodion before being placed into the slicer.

\section{Results and Discussion}

\subsection{Twist Effect on Wicking and Strength Properties of Ring Spinning Staple Yarns}

The wicking and the strength properties of the polyester ring spinning staple yarns at various twist levels are presented in Table 1. 
The results show that with an increase in the twist level, the staple yarns' wicking property deteriorated (with correlation coefficient $\left.R^{2}=-0.98\right)$ and the yarn strength improved $\left(R^{2}=\right.$ $0.94)$. The strength of the staple yarns was reduced to a very low degree when the twist level was lower than 740 (twist $/ \mathrm{m}$ ), while the strength irregularity increased significantly $(>14 \%)$ at these twist levels. However, at these twist levels, that yarn structure also became unsteady and the spinning process could not produce yarn when the twist level was lower than 545 (twist $/ \mathrm{m}$ ). The impact of changing twist on the wicking properties of the filament yarns (i.e., wicking height firstly increases and then decreases with increasing twist level) was not reproduced for the staple yarns. Instead, the results indicate that the number of capillary channels is the dominant factor controlling staple yarns' wicking properties under a twist design.
The best way to improve the wicking height of the polyester staple yarns is to reduce the twist level; however, this also decreases the yarn strength (Table 1) and influences the process of fabric manufacturing. Therefore, an alternative way to improve wicking is needed.

The compact-siro spinning process is an efficient way to increase the yarn strength while realizing the same twist coefficient as that of ring-spun yarn [10]; the resultant product has a better fiber arrangement as well as a similar-plying effect, which can provide more capillary space for the wicking process. The compact-siro spinning process provides an efficient way to improve the moisture transport properties of staple yarns.

Table 1. Wicking height and strength of ring spinning staple yarns with different twist levels

\begin{tabular}{|c|c|c|c|c|}
\hline Twist Level (Twist/m) & Wicking Height (mm) & $\begin{array}{c}\text { Wicking Height } \\
\mathbf{C V}(\%)\end{array}$ & Yarn Strength (cN) & Yarn Strength CV(\%) \\
\hline 545 & 38.4 & 10.6 & 194.4 & 15.0 \\
\hline 610 & 32.5 & 11.0 & 220.5 & 14.4 \\
\hline 675 & 32.1 & 10.8 & 249.3 & 14.9 \\
\hline 740 & 31.2 & 11.5 & 253.5 & 12.6 \\
\hline 805 & 27.2 & 10.3 & 259.3 & 12.4 \\
\hline 870 & 26.2 & 10.9 & 259.6 & 10.4 \\
\hline 935 & 25.0 & 10.8 & 273.0 & 10.5 \\
\hline 1.000 & 24.3 & 9.5 & 275.0 & 10.9 \\
\hline 1.065 & 23.6 & 9.0 & 282.5 & 9.7 \\
\hline 1.130 & 21.5 & 8.7 & 297.0 & 10.1 \\
\hline 1.195 & 19.5 & 8.6 & 294.0 & 10.3 \\
\hline 1.260 & 17.2 & 8.8 & 297.00 & \\
\hline
\end{tabular}

Table 2. Wicking height and strength of compact-siro spinning staple yarns with different twist levels

\begin{tabular}{|c|c|c|c|c|}
\hline Twist Level (Twist/m) & Wicking Height (mm) & $\begin{array}{c}\text { Wicking Height } \\
\mathbf{C V}(\%)\end{array}$ & Yarn Strength (cN) & Yarn Strength CV(\%) \\
\hline 545 & 41.6 & 11.3 & 220.3 & 13.5 \\
\hline 610 & 35.9 & 10.8 & 240.3 & 13.2 \\
\hline 675 & 35.3 & 11.0 & 260.5 & 13.3 \\
\hline 740 & 33.7 & 10.5 & 270.4 & 12.3 \\
\hline 805 & 28.5 & 10.2 & 285.2 & 11.5 \\
\hline 870 & 28.3 & 10.1 & 310.3 & 9.8 \\
\hline 935 & 27.6 & 9.4 & 332.2 & 9.5 \\
\hline 1.000 & 27.5 & 9.3 & 337.1 & 9.9 \\
\hline 1.065 & 25.5 & 8.9 & 347.1 & 8.9 \\
\hline 1.130 & 22.5 & 8.8 & 354.6 & 8.8 \\
\hline 1.195 & 21.1 & 8.5 & 357.8 & 9.0 \\
\hline 1.260 & 19.0 & 8.6 & 362.2 & \\
\hline
\end{tabular}




\subsection{Twist Effect on Wicking and Strength Properties of Compact-siro Spinning Staple Yarns}

The wicking and the strength properties of the compact-siro spun yarns are presented in Table 2.

With a decrease in the twist levels, the compact-siro spinning staple yarns' wicking property was improved $\left(R^{2}=-0.98\right)$, while the strength of the yarns was also reduced $\left(R^{2}=0.98\right)$. The changes in wicking and strength of the compact-siro spinning yarns followed the same trends as those of the ring spinning yarns. The strength irregularity of the compact-siro spinning yarn improved significantly under the designed twist level compared with the ring spinning yarns, and the compact-siro effect was the main factor for this enhancement.

\subsection{Yarn Structures}

An improved yarn-spinning method to maintain a low twist level but with better yarn strength is necessary to improve fabric wicking. The compact-siro spinning process satisfied

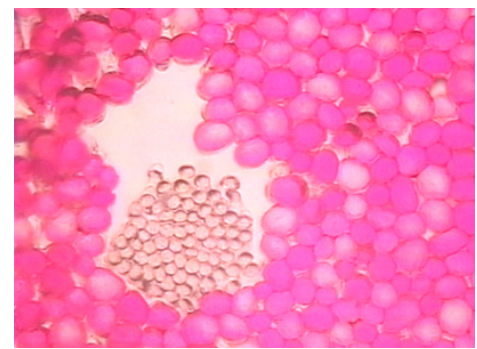

(a) Ring-spun yarn

Figure. 1 Cross-section structure of staple yarns

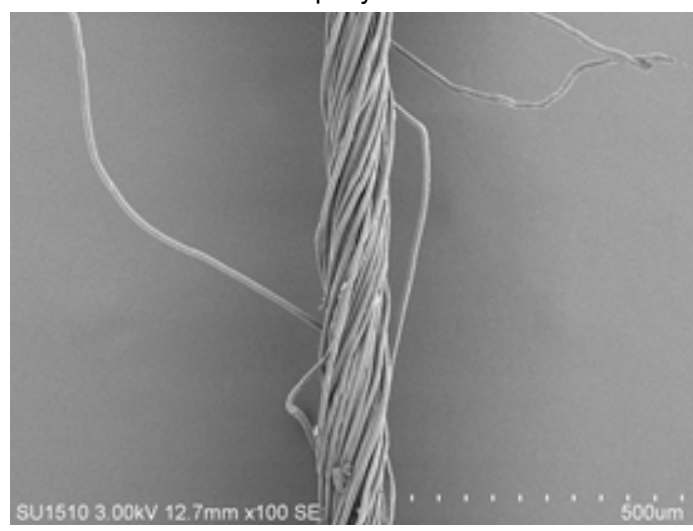

(a) Ring-spun yarn

Figure. 2 Longitudinal structure of staple yarns

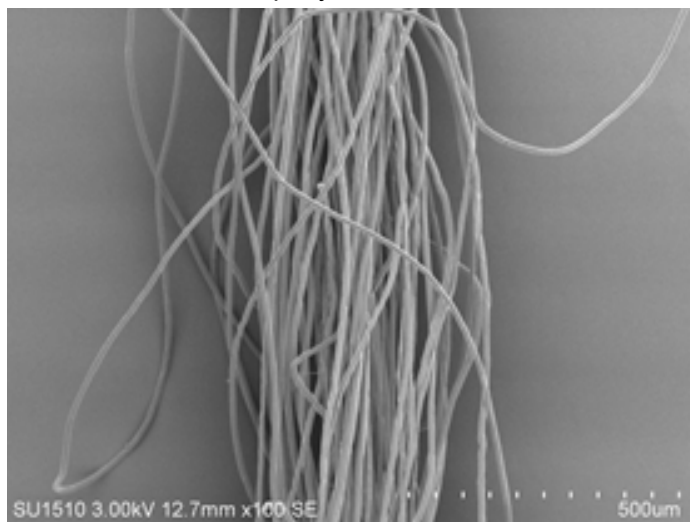

(a) Ring-spun yarn

Figure.3. Longitudinal structure of untwisted yarn http://www.autexr.com/ these requirements. A cross-sectional image obtained using a YG002C at $500 \times$ magnification is shown in Figure 1, while SEM (Hitachi SU1510; 100× magnification) images of the longitudinal structure of these two yarns are shown in Figure 2.

The images show that the compact-siro spun yarn is more compact than the ring-spun yarn. As such, the wicking property of the former should be inferior; however, this is not the case. This finding may be for two reasons. First is the increase in the number and continuity of the efficient wicking pores. As shown in Figure 1, the fibers in the center part of the yarn (ringing and compact-siro spinning) are closer to each other, and most of the pores would be easily blocked. The most efficient wicking pores are hidden in the surface parts of the yarn. However, the fiber arrangement in the compact-siro spun yarn is much better than that in the ring-spun yarn, resulting in a higher number of well-arranged, continuous wicking pores in the yarn surface, which improves the wicking property. Second, the plying effect of the compact-siro spun yarn results in a hidden channel at the center of the yarns, as shown in Figure 3.

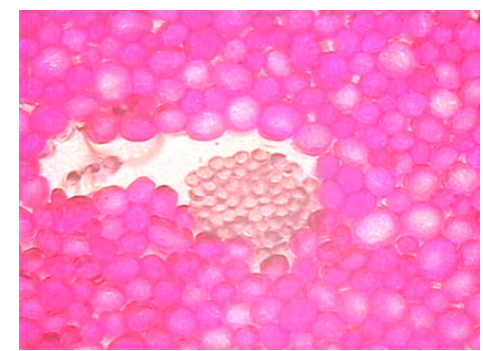

(b) Compact-siro Spun yarn

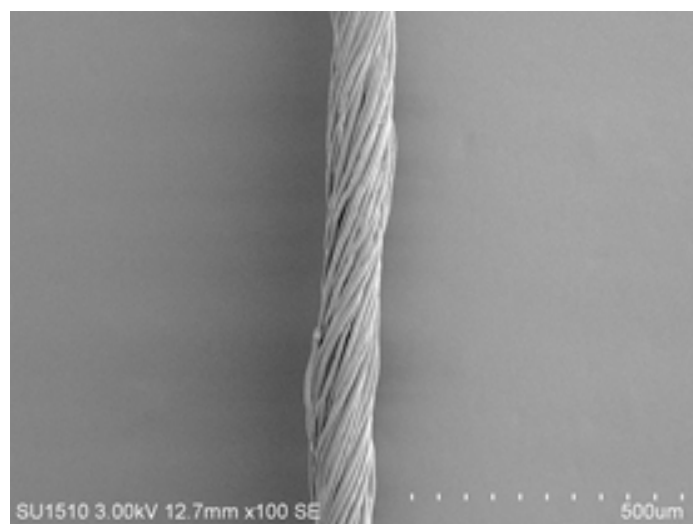

(b) Compact-siro spun yarn

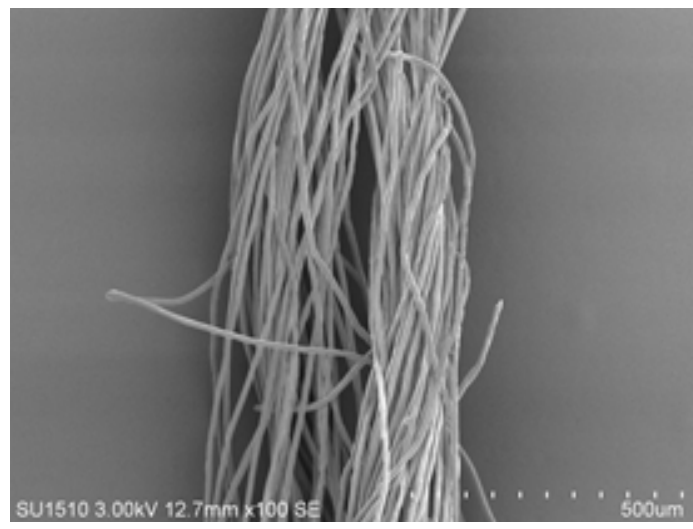

(b) Compact-siro spun yarn 
The plying effect of compact-siro spun yarn after the yarns are untwisted can be easily observed, and the hidden channel between two strands is exposed. The hidden capillary channel at the center of the yarns should be very efficient for moisture transfer, and as a result, the yarn wicking heights should be increased.

\subsection{Wicking Properties of the Two Yarns}

The comparative wicking heights and strengths of the two yarns are shown in Figures 4 and 5, respectively.

As shown in Figure 4, the wicking property of the compact-siro spun yarns is much better than that of the ring-spun yarns at the same twist level. The wicking height of the compact-siro spun yarns is higher than the ring spun yarns by about $10 \%$. The increase in the number of capillary channels in the surface of the yarns as well as the hidden channels among the two strands should be the main reason for this.

As is shown in Figure 5, the strength of the compact-siro spinning yarn was enhanced significantly compared with that of the ring-spinning yarn, especially when the twist level was increased to more than $800 \mathrm{twist} / \mathrm{m}$. The compact and siro effects should simultaneously improve the yarn strength.

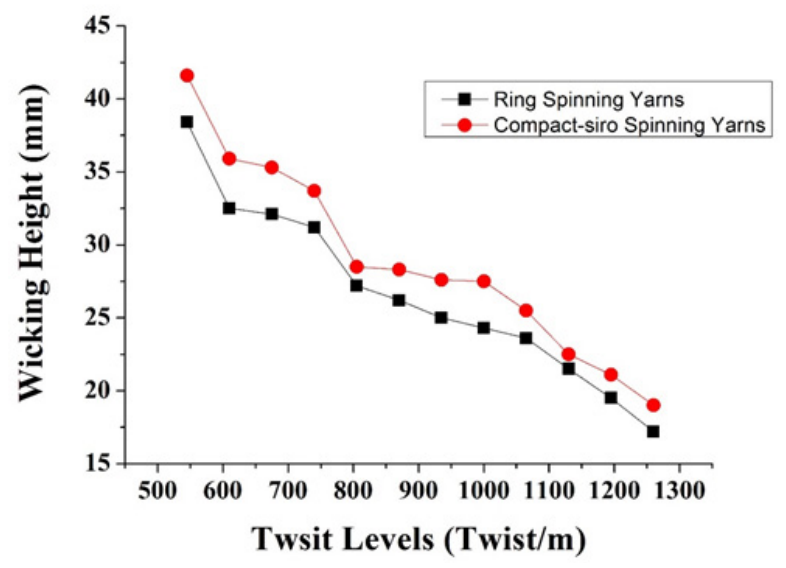

Figure. 4 Wicking height comparison

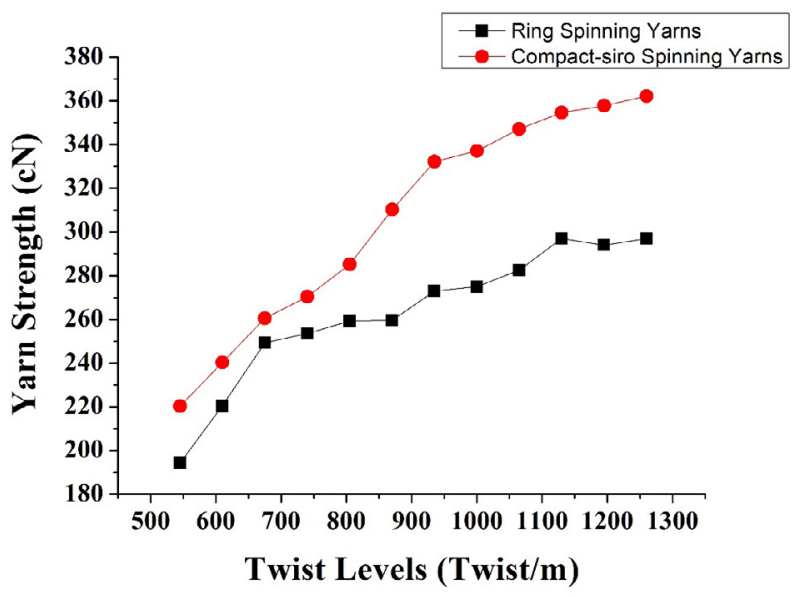

Figure. 5 Yarn strength comparison
For 9.7-tex polyester staple yarns, compact-siro spinning yarns can be produced under a twist of 805 (with a twist coefficient 250). At that twist level, the yarn strength is close to the strength of ring spinning yarn under a twist of 1,065 (a twist coefficient 330 ), which is suitable for a weaving process in which the wicking height can be enhanced by more than $20 \%$ (from 23.6 to $28.5 \mathrm{~mm}$ ). Furthermore, the yarn produced in a lower twist level results in great efficiency in the yarn production. This in turn makes compact-siro spinning an efficient process for improving the wicking property of staple yarns with lower twist and better yarn strength.

\section{Conclusions}

In this study, a simple capillary rise test was used to study the influence of yarn twist on the wicking property of staple yarns (ringing and compact-siro spinning). Low-moisture-regain polyester fibers were used to determine the real relationship between the two characteristics, namely, the staple yarn twist and the wicking property. The compact-siro spinning process was found to improve the staple yarns' strength and wicking property, and the following conclusions were made:

1. With an increase in the twist level, the wicking height of staple yarns decreases. In other words, a lower twist level can improve the wicking property of staple yarns significantly.

2. The compact-siro spinning process is efficient for producing yarns with low twist levels but high strength, thus ensuring good staple yarn wicking and high yarn production efficiency.

\section{ACKNOWLEDGMENTS}

This study was funded by the National Key R\&D Program of China (2017YFB0309200) and the Enterprise University Research Prospective Program of Jiangsu Province (No. BY2016022-16).

\section{References}

[1] Chandrasekaran, V., Senthilkumar, P., Karthik,T.(2016). Optimization of spinning parameters influencing the characteristics of structurally modified viscose yarn. The Journal of The Textile Insititue. 107(1), 50-63.

[2] Das, B., Das, A., Kothari,V.K., Fangueiro, R. (2011). Development of mathematical model to predict vertical wicking behaviour. part $i$ : flow through yarn. Journal of the Textile Institute, 102(11), 957-970.

[3] Erdumlu, N., Saricam, C.(2013). Wicking and drying properties of conventional ring- and vortex-spun cotton yarns and fabrics. The Journal of The Textile Institute. 104(12), 1284-1291.

[4] Hajiani, F., Ghareaghaji, A. A., Jeddi, A. A. A., Amirshahi, S. H., Mazaheri, F. (2014). Wicking properties of polyamide 66 twisted nanofiber yarn by tracing the color alteration in yarn structure. Fibers \& Polymers, 15(9), 1966-1976. 
[5] Houshyar,S., Padhye, R., Nayak, R.(2017). Effect of Moisture-wicking Materials on the Physical and Thermophysiological Comfort Properties of Firefighters' Protective Clothing. Fibers and Polymers, 18(2): 383-389.

[6] Kumar,P., Sinha,S.K., Ghosh, S.(2016). Estimation of Pore Size and Porosity of Modified Polyester/PVA Blended Spun Yarn. Fibers and Polymers.17(9): 1489-1496.

[7] Park, Y. (2016). Study of moisture and thermal transfer properties as a function of the fiber material variation. Fibers \& Polymers, 17(3), 477-483.

[8] RChattopadhyay. (2005). Wicking behavior of compact and ring spun yarns and fabrics. Melliand-china.11, 25.

[9] Schoenmaker, B. D., Schueren, L. V. D., Vrieze, S. D., Westbroek, P., Clerck, K. D. (2011). Wicking properties of various polyamide nanofibrous structures with an optimized method. Journal of Applied Polymer Science, 120(1), 305-310.

[10] Su, X., Gao, W., Liu, X., Xie, C., \& Xu, B. (2015). Research on the compact-siro spun yarn structure. Fibres \& Textiles in Eastern Europe, 23(3(111)), 54-57.
[11] Taheri,M., Vadood,M., Johari,M. S.(2013). Investigating the Effect of Yarn Count and Twist Factor on the Packing Density and Wicking Height of Lyocell Ring-spun Yarns. Fibers and Polymers. 14(9), 1548-1555.

[12] Tyagi, G. K., Krishna, G., Bhatlacharya, S., Kumar, P. (2009). Comfort aspects of finished polyester-cotton and polyester-viscose ring and mjs yarn fabrics. Indian Journal of Fibre \& Textile Research, 34(2), 137-143.

[13] Uzun, M. (2013). Effect of ultrasonic laundering on thermophysiological properties of knitted fabrics. Fibers \& Polymers, 14(10), 1714-1721.

[14] Wang,N., Zha,A.X., Wang, J.X. (2008). Study on the Wicking Property of Polyester Filament Yarns. Fibers and Polymers, 9(1), 97-100.

[15] Wang,Z.T., Zhao, J.J., Bagal, A., Dandley, E. C., Oldham, C.J.et al. (2016) Wicking Enhancement in ThreeDimensional Hierarchical Nanostructures. American Chemical Society. 32, 8029-8033. 